\title{
How should be the laboratory application? Prospective teachers' perspective
}

\author{
Fatma Alkan ${ }^{1, *}$ \\ ${ }^{1}$ Hacettepe University, Faculty of Education, 06800, Beytepe, Ankara, Turkey
}

\begin{abstract}
The importance and effectiveness of laboratory applications should be find out by students or teachers. The aim of this study is to examine the perceptions on laboratory applications of prospective teachers and to determine the opinions about chemistry laboratory practices. The study group consisted of 1st grade prospective teachers. The research has been designed in a mixed method design. In the quantitative dimension of the study, the data obtained from the perceptions on laboratory applications scale were analysed. In the qualitative dimensions of the study was carried out in accordance with the situation pattern, and focus group interviews were conducted. According to quantitative findings of the research, the highest scores of sub-scales is in the effectiveness of laboratory. In qualitative findings, it has been emphasized that laboratory applications still bring chemistry lessons more enjoyable, provide knowledge retentions with practical applications, develop responsibility, improve the preparation behaviour of the course.
\end{abstract}

\section{Introduction}

Science educators emphasize that practicing science is an effective way for students to learn concepts, keep knowledge in mind, and use scientific knowledge. Practical activities and laboratory education have an important place in improving science achievement and mental development [1]. Laboratory methodology is defined as a method in which students learn by doing research in laboratories or specially equipped classes, either as individuals or in groups. They make observations, conduct experiments, and learn through experience and demonstration. Although laboratory study is accepted as a fundamental and helpful part of science education, many studies have shown that laboratory education has not properly reached its objective.

Experimental studies are considered to be a fundamental part of a science course and are particularly applicable to chemistry courses. It is often assumed that chemistry is a practicebased science, and which provides sufficient justification for the existence of laboratory studies. Therefore, the development of students' ability to work in laboratory and conduct an experiments in laboratory is often desirable [2]. It is important to determine the aims and set out the objectives in the laboratory work. Laboratory work is generally defined as

\footnotetext{
* Corresponding author: alkanf@hacettepe.edu.tr
} 
practical experiment activities which students using chemicals and equipment in chemistry laboratory [3].

\subsection{The aim of the study}

Laboratory applications should be most done in the field of chemistry in the science courses at school. It will not be possible to learn abstract chemistry concepts without using laboratory and designing an experiment. Laboratory applications help students to organize their own knowledge, develop problem solving skills and psychomotor skills, and reveal a positive attitude towards chemistry. The importance and effectiveness of laboratory applications should be find out by students or teachers. The aim of this study is to examine the perceptions on laboratory applications of prospective teachers and to determine the opinions about chemistry laboratory practices.

\section{Method}

The model of the study is the case study from the descriptive survey model. The case study model aims to make an in-depth judgment about a particular situation in the universe by identifying the relationship between itself and its environment [4]. The study group consisted of 1st grade prospective teachers studying at Hacettepe University, Faculty of Education.

\subsection{Data collection tools}

The perceptions on laboratory applications scale was used as data collection tool [5]. The scale consists of 20 items in 5-point Likert type. The scale has three sub-scales: goals of laboratory applications, effectiveness of laboratory and planning. The Cronbach alpha reliability coefficient of the scale is 0.88 for the whole scale and for the sub-scales are between $0.92,0.80$ and 0.70 .

Focus group interviews were conducted in order to examine in-depth prospective teachers' thoughts about laboratory practices and their difficulties. An interview form was prepared and it consists of 5 questions about the sub-dimensions of the perceptions on laboratory applications scale.

\subsection{Data analysis}

Analysis of the data obtained from the study was performed with the SPSS 17 packet program. Descriptive statistics were performed primarily when analysis of data from scales was performed. Thus, the opinions of the sample group about perceptions on laboratory applications were determined. Focus group interviews were held on the methodological activities with prospective teachers'. The obtained data were analyzed and codes related to laboratory applications were determined. Findings have helped explain quantitative results.

\section{Results}

\subsection{Quantitative findings}

Descriptive statistics related to pre-test scores of prospective teachers' instructional materials motivation level before scientific inquiry in chemistry laboratory application are summarized in Table 1. 
Table 1. Descriptive statistics of scale

\begin{tabular}{|c|c|c|c|c|}
\hline & $\mathbf{X}$ & sd \\
\hline Scale & \multicolumn{2}{|c|}{ Perceptions on laboratory applications } & 4.44 & .39 \\
\hline & \multirow{3}{*}{ 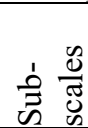 } & Goals of laboratory applications & 4.39 & .59 \\
\hline & & Effectiveness of laboratory & 4.70 & .67 \\
\hline & & Planning & 4.05 & .61 \\
\hline
\end{tabular}

When the table is examined, it is seen that the pre-service teachers' perception levels towards laboratory applications are high level (X:4.44) and the highest average in the subdimensions is the effectiveness of the laboratory $(\mathrm{X}: 4.70)$.

\subsection{Qualitative findings}

Audio video recording was used in interviews with prospective teachers about chemistry laboratory practices. After evaluating the data obtained from the research, it was determined that the opinions of prospective teachers about chemistry laboratory applications were gathered in different categories.

According to focus group interviews with the prospective teachers the codes were adjusted. The codes and the students who gave their opinions are summarized in Table 2.

Table 2: Findings on perceptions of laboratory applications

\begin{tabular}{|l|l|}
\hline Codes & Students \\
\hline How should laboratory applications be? & S1, S4, S6, S11, S14, S17 \\
\hline
\end{tabular}

Sample expressions of the code are given below.

$\mathrm{S} 1: . .$. It is better if the student enters the laboratory and conducts an experiment that he finds.... Experiments will be more effective in learning if they are conducted individually rather than in groups....

S4:... laboratory rules must be followed....

S7: ..... work safely so as not to harm other experimenters....

How should laboratory applications be? code supports the goals of laboratory applications sub-dimension of perceptions on laboratory applications scale.

From focus group interviews contribution of laboratory applications to hardware code were adjusted. Information about the code is given in the Table 3.

Table 3: Findings on contribution of laboratory applications to hardware

\begin{tabular}{|l|l|}
\hline Codes & Students \\
\hline $\begin{array}{l}\text { Contribution of laboratory applications to } \\
\text { hardware }\end{array}$ & S2, S3, S7, S12, S13, S15, S19 \\
\hline
\end{tabular}

Sample expressions of the code are given below.

S3:... Laboratory practice has improved my dexterity and I have learned how to use many materials....

S7:.... I understand that you need to be careful when working with chemicals...

S15: ..... if we don't have enough information, we can make mistakes while experimenting and endanger ourselves and those around us....

The contribution of laboratory applications to hardware code supports the effectiveness of the laboratory sub-dimension of perceptions on laboratory applications scale. 
According to focus group interviews with the prospective teachers the codes were adjusted. The codes and the students who gave their opinions are summarized in Table 4.

Table 4: Findings on importance of laboratory

\begin{tabular}{|l|l|}
\hline Codes & Students \\
\hline Importance of laboratory & S5, S8, S9, S10, S16, S18, S20 \\
\hline
\end{tabular}

Sample expressions of the code are given below.

$\mathrm{S} 5$ :.... practical applications are important in chemistry, we understand the knowledge better by experimenting....

$\mathrm{S} 9: . .$. the theoretical knowledge will become more meaningful if it is done after the practical application after learning the theoretical knowledge.....

$\mathrm{S} 18: . .$. it is more difficult for a person to forget what he is doing and he recognizes the mistakes in an action more quickly than the error in thought and learns the truth more easily....

The importance of laboratory code supports the planning sub-dimension of perceptions on laboratory applications scale.

\section{Discussion and Conclusion}

As a result of this research, it was found out that prospective teachers' perceptions of the laboratory were quite high with quantitative data, at the same time it was found that this results supported by qualitative data. Prospective teachers have the highest average in the effectiveness of the laboratory of the perception on laboratory applications scale. In addition, it has been emphasized that laboratory practices make chemistry courses more enjoyable, ensure the persistence of knowledge with practical applications, improve responsibility awareness, increase preparedness to come to class, and gain the ability to work individually and in groups. It is considered that many abstract chemistry concepts cannot be learned in chemistry education, where laboratory studies are applied intensively, without the use of laboratories and experiments, and that the desired achievement can be achieved by gaining the ability to apply laboratory usage and approaches in chemistry education process.

According to qualitative findings obtained from the focus group interviews with the 1 st grade prospective teachers the codes were determined. Codes are grouped under these headings: "How laboratory work should be", "What does laboratory applications add to our equipment", "Why laboratory applications are important." In qualitative findings, it has been emphasized that laboratory applications still bring chemistry lessons more enjoyable, provide knowledge retentions with practical applications, develop responsibility, improve the preparation behaviour of the course, and provide individual and group working skills. It can be said that there is a relationship between the sub-dimensions of the perceptions on laboratory applications scale and codes.

Some expressions of prospective teachers is in how laboratory work should be code, such as "... it may be more useful to conduct an experiment individually in the laboratory... and .... experiments are more efficient if done individually. Because when a person is doing a process, the group mate is watching, which causes a lack of laboratory equipment." These expressions relate to goals of laboratory applications sub-scale. What does laboratory applications add to our equipment codes expressions are "...laboratory has improved my hand skills. I've learned how to use the material.... and ... taught me how to use the materials. In experiments with chemicals we need to be very careful." This code is related to the effectiveness of laboratory sub-scale. The expressions associated with why laboratory 
applications are important code, “....practical work is of great importance. We can better understand the information by doing the experiment... and .... with the theoretical and practical work, the information becomes more permanent." This code is also associated with the planning sub-scale. The qualitative findings of the study support the quantitative findings.

Each classroom has a special learning environment and students in the classroom are more or less affected by this environment [6]. There are strong ties between the learning environment variables in the classroom and students' cognitive and affective learning products [7]. Laboratory work create a different learning environment in many respects than classical classroom environments. Perception of laboratory work by students and its effect on success has been discussed in many studies $[8,9,10]$. According to research, students enjoy laboratory work and state that laboratory experiences result in positive and improved student attitudes and interest science [11, 12]. The laboratory work will contribute to the learning of chemistry and other sciences, will gain the ability to comprehend interdisciplinary relations, and develop a sense of responsibility.

Why learning environments of such importance cannot be used more effectively. One of the shortcomings of our education system is that the laboratory environments, which are perceived as important by students and prospective teachers, remain in the secondary chemistry curriculum with only theoretical experiments and that students enter the laboratory for the first time. What happens to prospective teachers with high perceptions in the university, but when they become teachers, they appear as people who are afraid to enter the laboratory, researching this situation requires that both the university and national education stakeholders do their part. In this study, laboratory perceptions of prospective chemistry teachers were examined. The results to be developed in the sample group can be searched, studies can be conducted with the teachers working in national education and the results can be compared.

\section{References}

1. H. Ertepinar, O. Geban, Educ. Res., 38, 3 (1996).

2. J. Carnduff, N. Reid, Enhancing undergraduate chemistry laboratories, pre-laboratory and post-laboratory exercises, examples and advice, (London: Piccadilly, 2003).

3. N. Reid, I. Shad, Chem. Educ. Res. Pract., 8, 2 (2007).

4. N. Karasar, Scientific Research Method. (Ankara: Nobel Press 2009).

5. B. Feyzioglu, B. Demirdag, M. Akyildiz, E. Altun, Educ. Sci.: Theo. Prac., 12, (2012).

6. K. Açıkgöz, A research on the classroom atmosphere in high schools. Educational Sciences Symposium Proceedings. Inönü University, Education Faculty Malatya (1989).

7. B.J. Fraser, Research on classroom and school climate. In D:Gabel (Ed.), Handbook of research on science teaching and learning. (New York: Macmillan 1994).

8. B.J. Fraser, C.J. McRobbie, Educ. Res. Eval., 1, (1995).

9. A. Hofstein, I. Cohen, Res. Sci. Techn. Educ., 14, 1 (1996).

10. D. Doğan, E.E. Doğan, H. Atılgan, K. Batçıŏlu, B. Demirci, Evaluation of the general chemistry laboratory class environment in different universities in educational faculties. V. National Science and Mathematics Education Congress, Ankara (2002).

11. A. Hofstein, V. N. Lunetta, Sci. Educ., 88, 1 (2004).

12. C. Koçak, J. of Balt. Sci. Educ., 12, 5 (2013). 